\title{
Improved Biological Responses of Titanium Coating Using Laser-Aided Direct Metal Fabrication on SUS316L Stainless Steel
}

\author{
Tae-In Kim ${ }^{1,+(\mathbb{D})}$, Se-Won Lee ${ }^{2,3,+}{ }^{\mathbb{D}}$, Woo-Lam Jo ${ }^{2,4}$, Yong-Sik Kim ${ }^{2,4}$, Seung-Chan Kim ${ }^{2,5}$, Soon-Yong Kwon ${ }^{2,5}$ \\ and Young-Wook $\operatorname{Lim}^{2,4, * \mathbb{D}}$
}

1 Department of Orthopaedic Surgery, Davos Hospital, Yongin-si, Gyeonggi-do 17063, Korea; 77linus@daum.net

2 Department of Orthopaedic Surgery, College of Medicine, The Catholic University of Korea, Seoul 06591, Korea; ssewon@naver.com (S.-W.L.); jis25@naver.com (W.-L.J.); yongsik@korea.com (Y.-S.K.); kschb129@naver.com (S.-C.K.); sykwon@catholic.ac.kr (S.-Y.K.)

3 Department of Orthopaedic Surgery, Yeouido St. Mary's Hospital, College of Medicine, The Catholic University of Korea, Seoul 07345, Korea

4 Department of Orthopaedic Surgery, Seoul St. Mary's Hospital, College of Medicine, The Catholic University of Korea, Seoul 06591, Korea

5 Department of Orthopaedic Surgery, Eunpyeong St. Mary's Hospital, College of Medicine, The Catholic University of Korea, Seoul 03312, Korea

* Correspondence: albire00@naver.com

+ These authors contributed equally to this work.

Citation: Kim, T.-I.; Lee, S.-W.; Jo, W.-L.; Kim, Y.-S.; Kim, S.-C.; Kwon, S.-Y.; Lim, Y.-W. Improved Biological Responses of Titanium Coating Using Laser-Aided Direct Metal Fabrication on SUS316L Stainless Steel. Materials 2021, 14, 3947. https://doi.org/ $10.3390 / \mathrm{ma} 14143947$

Academic Editor: Jordi Sort

Received: 3 June 2021

Accepted: 13 July 2021

Published: 14 July 2021

Publisher's Note: MDPI stays neutral with regard to jurisdictional claims in published maps and institutional affiliations.

Copyright: (c) 2021 by the authors. Licensee MDPI, Basel, Switzerland. This article is an open access article distributed under the terms and conditions of the Creative Commons Attribution (CC BY) license (https:// creativecommons.org/licenses/by/ $4.0 /)$.

\begin{abstract}
Direct metal fabrication (DMF) coatings have the advantage of a more uniform porous structure and superior mechanical properties compared to coatings provided by other methods. We applied pure titanium metal powders to SUS316L stainless steel using laser-aided DMF coating technology with 3D printing. The purpose of this study was to determine the efficacy of this surface modification of stainless steel. The capacity of cells to adhere to DMF-coated SUS316L stainless steel was compared with machined SUS316L stainless steel in vitro and in vivo. Morphological in vitro response to human osteoblast cell lines was evaluated using scanning electron microscopy. Separate specimens were inserted into the medulla of distal femurs of rabbits for in vivo study. The distal femurs were harvested after 3 months, and were then subjected to push-out test and histomorphometrical analyses. The DMF group exhibited a distinct surface chemical composition, showing higher peaks of titanium compared to the machined stainless steel. The surface of the DMF group had a more distinct porous structure, which showed more extensive coverage with lamellipodia from osteoblasts than the machined surface. In the in vivo test, the DMF group showed better results than the machined group in the push-out test (3.39 vs. $1.35 \mathrm{MPa}$, respectively, $p=0.001$ ). In the histomorphometric analyses, the mean bone-to-implant contact percentage of the DMF group was about 1.5 times greater than that of the machined group $(65.4 \pm 7.1 \%$ vs. $41.9 \pm 5.6 \%$, respectively; $p<0.001)$. The porous titanium coating on SUS316L stainless steel produced using DMF with 3D printing showed better surface characteristics and biomechanical properties than the machined SUS316L.
\end{abstract}

Keywords: titanium; direct metal fabrication; metal 3D printing; stainless steel

\section{Introduction}

Metallic biomaterials have several essential properties, such as high corrosion resistance, biocompatibility, osseointegration, durability, and mechanical strength [1,2]. Titanium (Ti) alloy satisfies these requirements and has several advantages over other materials, such as cobalt-based alloys and SUS316L stainless steel, but is disadvantageous in terms of its cost effectiveness and its manufacturing process [3-5].

Cost effectiveness may be the most important factor in the absence of differences in clinical results among metals. Moreover, easier manufacturing processes also result in 
reduced production costs. Stainless steel has advantages over Ti alloy in terms of its lower cost and ease of manufacture $[6,7]$.

Stainless steel shows good biocompatibility. Austenitic 316L SS is well known for its versatility, owing to its outstanding mechanical properties, such as corrosion resistance. Surface coatings are applied when used in biomedical instruments requiring temporary contact [8]. Even with its decent in vitro corrosion resistance, SS has disadvantages such as material transfer between sliding bodies, oxidation, mechanical mixing, strain-induced martensitic transformation, and poor wear resistance [9]. Furthermore, rather than achieving direct bone-implant contact, there is a propensity for a fibrous tissue interface to develop between stainless steel implants and bone, rendering this material inferior to $\mathrm{Ti}$ alloy in the field of biomedical applications $[3,4,10]$.

Surface-engineered materials or coating composites are designed to distinctively improve biological properties, as well as tribological, optical, electrical, and chemical properties, among others. Various trials of coatings materials and coating techniques have been carried out with the aim of reducing wear, corrosion and friction. Titanium (Ti) is a representative substance that is used for biomedical device coatings [11,12]. The typical techniques utilized for coatings on 316L stainless steel include sol-gel methods [12,13], filtered arc deposition methods [11,14], physical vapor deposition methods [15,16], magnetron sputtering $[17,18]$, and plasma nitriding methods [19]. Recently, Shin and Kim et al. presented a laser-engineered net shaping coating technology [20]. This coating technology was developed to overcome the limitations of conventional coating methods. They used laser-aided direct metal fabrication (DMF) with 3D printing technology. Its utility as a surface coating technology for artificial joints was evaluated. DMF technology with 3D printing is a newly developed coating method that is cost-effective and maintains mechanical strength. Idealistic surface profiles such as maximum porosity/roughness and suitable pore size can be achieved with this technology. Furthermore, a solid interface between the coating and the substrate can be achieved despite the different properties of the coating and substrate [20].

We studied whether titanium powder coating on stainless steel with DMF technology could improve biological responses compared to machined SUS316L, as reflected by: (1) the chemical composition of the coating surface; (2) the porosity of the coating surface; (3) the cell morphology; (4) the interfacial shear strength measured by push-out test; and (5) bone histomorphometry.

\section{Materials and Methods}

We compared Ti-coated SUS316L stainless steel (SUS 316L (ASTM F138-19), Titanium Industries, Inc., Rockaway, NJ, USA) using DMF (SUS-DMF) with machined SUS316L stainless steel (SUS-machined) in vitro and in vivo. Two types of stainless steel were subjected to assessment of the chemical composition and structure of the surface in vitro. Two types of stainless steel SUS316L discs with diameter of $12 \mathrm{~mm}$ and thickness of $10 \mathrm{~mm}$ were manufactured $(n=20)$ : (1) SUS-machined $(n=10)$ and (2) SUS-DMF types $(n=10)$. Additionally, two types of stainless steel rods (diameter: $2.7 \mathrm{~mm}$; length: $27 \mathrm{~mm}$ ) were manufactured $(n=32)$ : (1) SUS-machined $(n=16)$ and (2) SUS-DMF types $(n=16)$, for in vivo study.

\subsection{Manufacturing of the SUS-DMF Specimens}

Stainless steel surface was irradiated with a high-powered laser to liquefy and coat pure Ti metal powders (Ti powder: 45-150 $\mu \mathrm{m}$, ASTM F1580-18 (grade 2), Advanced Powders and Coatings, Inc. (AP\&C), Boisbriand, QC, Canada). A 3D computer-assisted design (CAD) program was used to construct the porous structure; materials with similar properties of cancellous bone were matched to confer acceptable fixation force [20]. To protect the porous structure from oxidation during the manufacturing process, continuous argon gas was used for the shielding. The gas flow rate for shielding was $7 \mathrm{~L} / \mathrm{min}$. 
The first coating layer, with an average thickness of $300 \mu \mathrm{m}$, was laminated, with the subsequent second layer having an average thickness of $500 \mu \mathrm{m}$. The variation in the thicknesses confers further irregularity in the coating profiles.

An optical interferometer (Accura 20001; Interplus corporation, Seoul, Korea) was used to measure the surface roughness. The average surface roughness was $6.1 \pm 0.23 \mu \mathrm{m}$ [mean \pm standard deviation] for the SUS-DMF group and $0.2 \pm 0.14 \mu \mathrm{m}$ for the SUSmachined group. After laminating the test samples with platinum, they were analyzed with scanning electron microscopy (SEM; JSM-6700F; JEOL Ltd., Tokyo, Japan).

\subsection{Surface Chemical Composition and Porosity}

After coating the test specimens, the chemical composition and porosity of two surfaces were examined using energy-dispersive X-ray spectroscopy (EDS; xFlash 6i100, Bruker, Billerica, MA, USA) and SEM, respectively.

\subsection{Culture and Osteogenic Differentiation process of Human Mesenchymal Stem Cells (hMSCs)}

Bone marrow-derived hMSCs at passage 2 were acquired from the Catholic Institute of Cell Therapy (Seoul, Korea). Markers such as positive markers (CD73 and 90) and negative markers (CD31, 34, and 45) were used for the confirmation of the certificates of analysis for the hMSC phenotype. hMSCs were cultured in Dulbecco's modified Eagle's medium (DMEM) (GE Healthcare Hyclone, Salt Lake City, UT, USA) supplemented with $20 \%$ fetal bovine serum (FBS) (GE Hyclone) and 1\% penicillin/streptomycin (Gibco-BRL, Grand Island, NY, USA) for five passages. The cells were kept at $37{ }^{\circ} \mathrm{C}$ for $24 \mathrm{~h}$ in a humidified incubator under an atmosphere of $5 \% \mathrm{CO}_{2}$. Culture of hMSCs at passage 6 led osteogenic differentiation using a Stem Pro Osteogenesis Differentiation Kit (Gibco-BRL). The osteogenesis differentiation basal medium was supplemented with gentamicin reagent. hMSCs were seeded in 6-well culture plates at a density of 3-9 $\times 10^{4}$ cells per $\mathrm{cm}^{2}$. The media on the culture plate were replaced every 3-4 days, with the total incubation period being 21 days.

\subsection{Preparation for Cell Morphology}

Osteoblasts derived from hMSCs were seeded at $5 \times 10^{4}$ cells on SUS-DMF and SUSmachined specimens. Six hours after seeding of cells, the media were removed, and the cells were cleansed three times with PBS. After adding $2 \%$ glutaraldehyde-PBS solution, the cells were stabilized for $2 \mathrm{~h}$ and then washed three times with distilled water (DW). At 30-min intervals, the cells were dehydrated using a 50-100\% ethanol series. The cells were left at room temperature for complete evaporation of any remaining ethanol. The specimens were coated with platinum, and two surfaces were then examined by SEM.

\subsection{Implantation of Coated Rods}

The experiments were performed in eight full-grown mature New Zealand white rabbits $(>3.2 \mathrm{~kg})$. The rabbits were anesthetized by intramuscular administration of ketamine (35 mg/kg) and Rompun ( $5 \mathrm{mg} / \mathrm{kg}$ ). With the animal in the supine position, longitudinal incision on each leg was made from $4 \mathrm{~cm}$ above the knee joint to $2 \mathrm{~cm}$ below. After the patella was turned over laterally, a hole was made in the medial femoral condyle using a 3.5-mm drill bit, which was filled with a rod coated with SUS-DMF. The contralateral femur was filled with a rod coated with SUS-machined, after going through the same process. After replacing the patella in its normal position, the dissected structures were subsequently repaired with Vicryl 2/0 sutures [21]. Twelve weeks later, the distal femurs were harvested in order to perform push-out tests and histological examinations.

Rabbits were placed separately in cages with a wire bottom in a room with controlled temperature and light. All rabbits were allowed to become familiar with the housing facility for 5-7 days prior to the intervention. They were allowed to have ad libitum access to water and food. Animal care, housing, and interventions complied with the protocol 
approved by the Institutional Animal Care and Use Committee (IACUC) of The Catholic University of Korea. (CUMC-2016-0006-05).

\subsection{Interfacial Shear Strength Measurement; Push-Out Test}

A push-out test was performed to determine the bonding strength to the bone. Every harvested distal femur was cut at both ends of the rod, and foreign bodies were removed. Each test piece was placed in a testing jig to enable the loading and longitudinal axes of the implant to be aligned accurately. The implants were pushed out from the bone sections with a Universal Testing Machine (DTU-900MH, DaeKyung Tech, Incheon, Korea) at a crosshead speed of $1 \mathrm{~mm} / \mathrm{min}$. The measured load was divided by the cortex-implant contact area to calculate the interfacial shear strength [21].

\subsection{Bone Histomorphometry}

After dehydrating the harvested bone tissue with alcohol, it was soaked in Technovit 7200 resin (Morphisto, Frankfurt, Germany). The soaked tissue was immersed in paraffin using a light system (Exakt Technologies Inc., Oklahoma City, Oklahoma). The blocks were sliced into sections $200 \mu \mathrm{m}$ thick with a solid tissue slicer (Struers, Willich, Germany), and each section was stained with hematoxylin and eosin (H \& E; Sigma-Aldrich, St. Louis, MI, USA). Microscopic pictures were procured at an original magnification of $\times 12.5$ (Bx51; Olympus, Tokyo, Japan). The percentage of direct contact between the mineralized bone and the stainless steel surface was determined for each harvested specimen, using an integrative eyepiece with parallel sampling lines at a magnification of $\times 100$.

\subsection{Statistical Analysis}

The mean interfacial shear strength and bone-to-implant contact percentage of the two different surfaces were calculated using Wilcoxon's signed-rank test. All statistical analyses were performed using SPSS ver. 20.0 (IBM Corporation, Armonk, NY, USA). In the performed analyses, $p<0.05$ was taken as the level of statistical significance.

\section{Results}

The chemical composition of the SUS316L surface in the two groups was evaluated with EDS. Compared to the SUS-machined specimens (Figure 1A), the SUS-DMF type presented a totally contrasting surface with high peaks of Ti (Figure 1B). In the SEM images, the surface of the machined SUS316L possessed a flat, monotonous appearance (Figure 2A). On the other hand, the surface of DMF had a more distinct porous structure than the machined surface (average pore size in the coating layer: $200-500 \mu \mathrm{m}$; average porosity: $62.4 \pm 7.1 \%$; coating thickness: $500 \pm 100 \mu \mathrm{m}$ ) (Figure 2B).

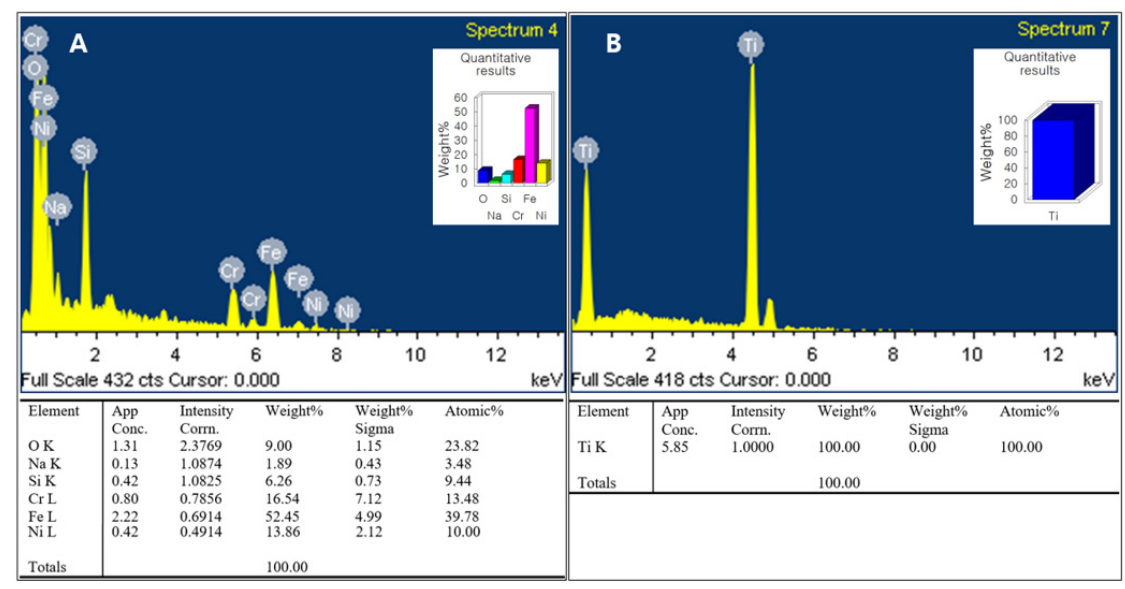

Figure 1. EDS of (A) the SUS-machined group and (B) the SUS-DMF group. Compared to (A) the machined specimen, (B) the SUS-DMF group showed an absolutely different pattern, showing high peaks of Ti. 


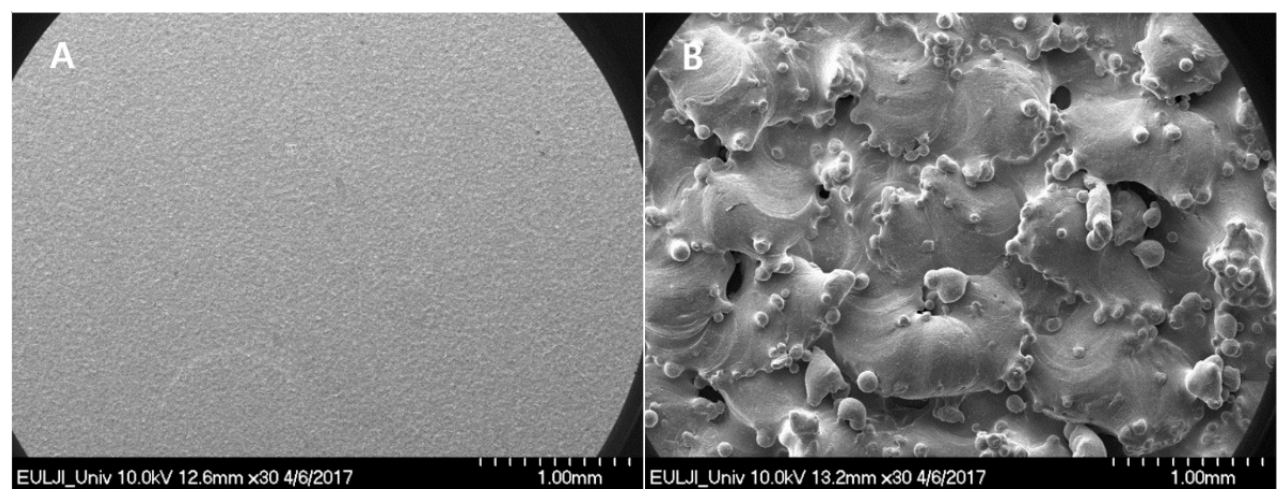

Figure 2. SEM images of the porous surfaces of $(A)$ the SUS-machined specimens $(\times 30)$ and $(\mathbf{B})$ the SUS-DMF specimens $(\times 30)$, showing the different surface properties. Compared with the machined surface, the SUS-DMF specimen exhibited a remarkable porosity, ranging from 200 to $500 \mu \mathrm{m}$.

With regard to cell morphology, after a 6-h incubation, the SUS-DMF surfaces were covered with more prominent lamellipodia from the osteoblasts (Figure 3A) than the machined surfaces (Figure 3A). In addition, thin cytoplasmic projections (filopodia) extended into the interior of the pores (Figure 3B).

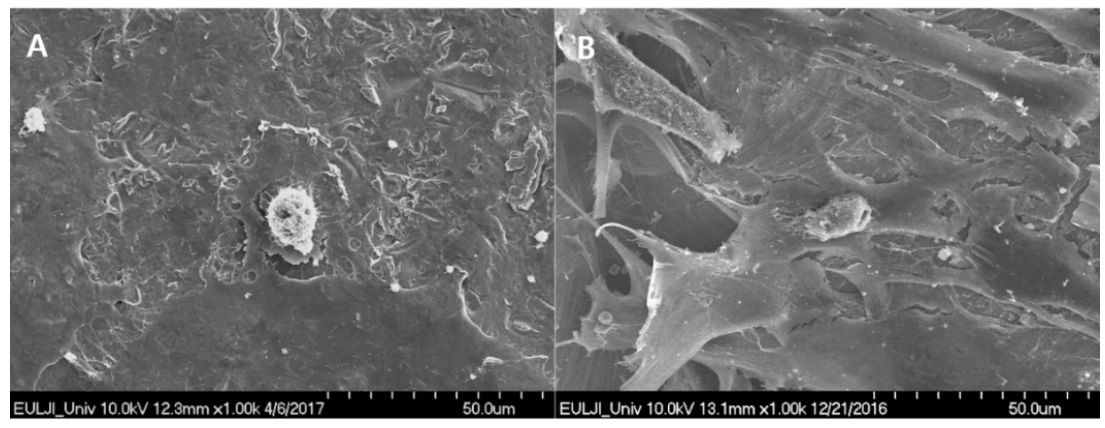

Figure 3. SEM images of osteoblast after $6 \mathrm{~h}$ of incubation on $(\mathrm{A})$ SUS-machined specimens $(\times 1000)$ and $(\mathbf{B})$ SUS-DMF specimens $(\times 1000)$. (A) The surface of the SUS-machined specimens was covered with sparse, small osteoblast cells. (B) The surface of the DMF specimens was firmly covered with large, healthy lamellipodia of osteoblast cells. Branches of thin cytoplasmic process from filopodia were seen entering the pores.

In the biomechanical push-out test, the ultimate shear strength in the DMF group (3.39 MPa) was 2.5 times greater than that in the machined group (1.35 MPa) $(p=0.001)$ (Figure 4).

The mean bone-to-implant contact percentage in the DMF groups $(65.4 \pm 7.1 \%)$ (Figure 5A) was 1.5 times that of the machined group $(41.9 \pm 5.6 \%)$ (Figure $5 \mathrm{~B})(p<0.001)$ in the histomorphometric analysis. The SUS-DMF group showed tighter attachment than the machined group. 


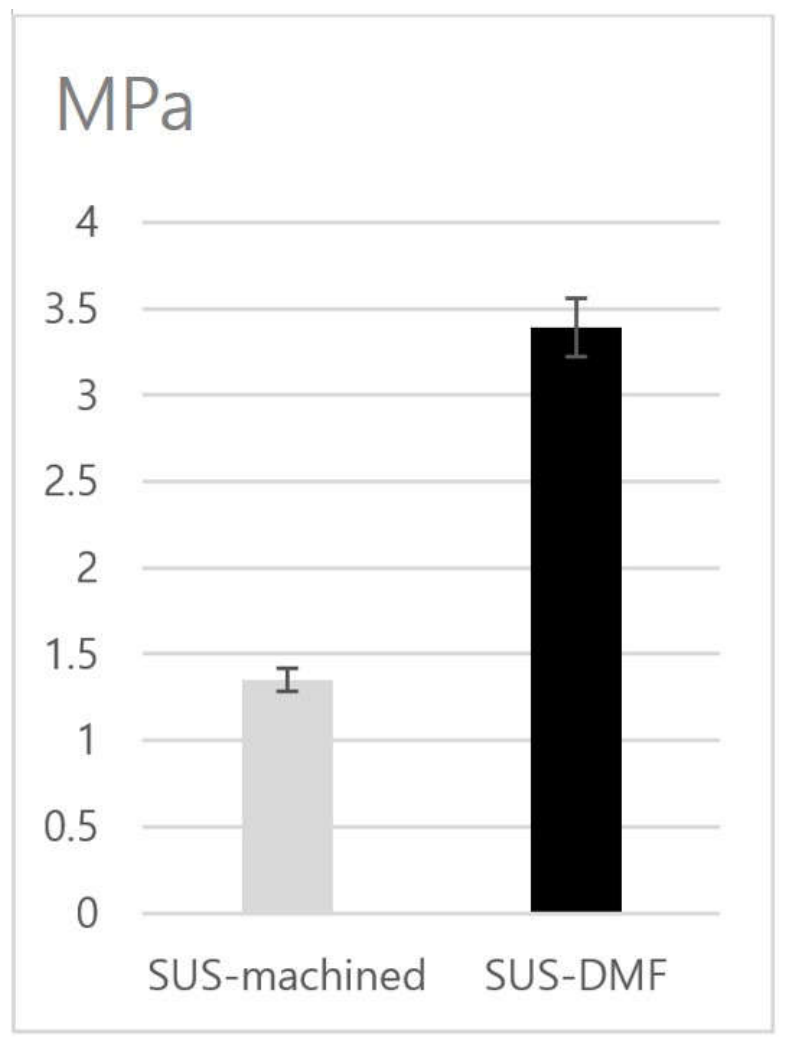

Figure 4. Results of the shear stress of the SUS-machined group and the SUS-DMF group in the push-out test.

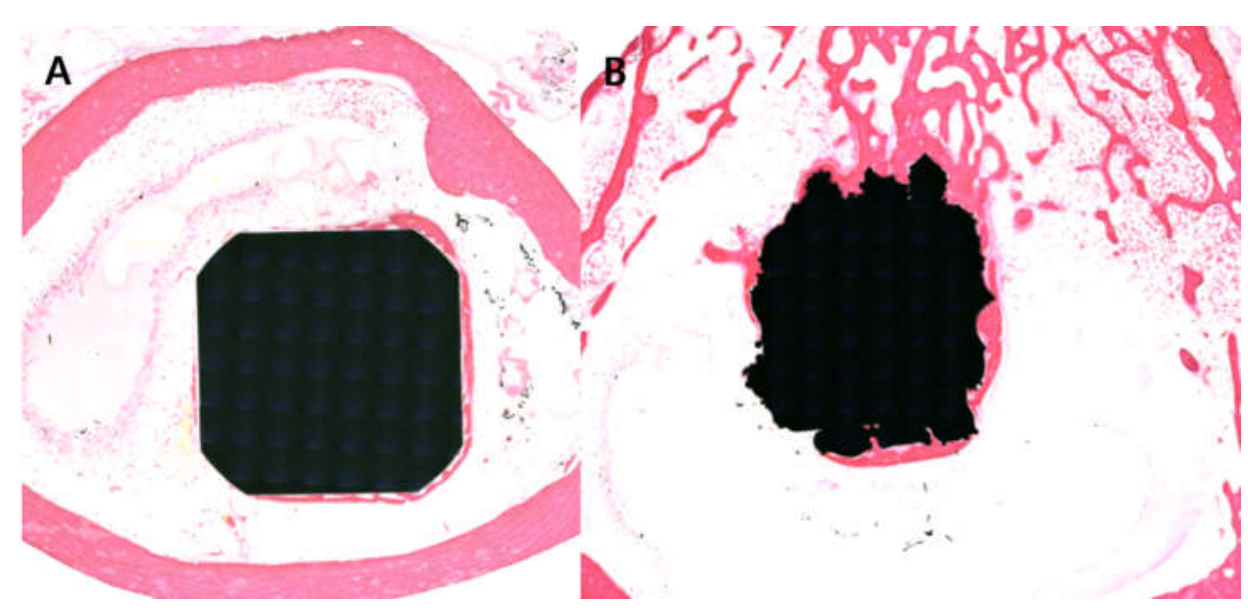

Figure 5. Light microscope images revealing the bone-to-implant contact of $($ A $)$ the SUS-machined $(\times 12.5)$ and $(\mathbf{B})$ SUS-DMF $(\times 12.5)$ samples. The bone-to-implant contact of the DMF group was superior to that of the machined group.

\section{Discussion}

The results of the present study demonstrate that Ti-coated stainless steel using DMF with 3D printing produces favorable biological surface characteristics and better biomechanical strength than machined SUS316L in vitro and in vivo.

Selective laser melting and electron beam melting are 3D printing methods that use an energy source to melt and fuse selected regions of the coating powder in accordance with CAD data [22]. The DMF method differs from other methods in how the coating powders are sprayed and laminated onto the surface. The DMF method has advantages over other $3 \mathrm{D}$ printing methods in terms of manufacturing time and ease of fabrication [20]. 
Use of DMF with 3D printing has the advantage of allowing control over the coating surface porosity, which is not possible with conventional methods [20,23]. We have previously reported an average porosity of $65 \pm 5 \%$ for DMF specimens with thicknesses ranging from 200 to $500 \mu \mathrm{m}$, which is a value that is similar to those found for human cancellous bone (50-90\%) [20]. Moreover, Ti is highly cytocompatible, which creates a more favorable structure for the attachment and proliferation of osteoblasts [2,24]. Keller et al. reported that surface porosity positively affects both osteoblast attachment and number [25]. Zhu and colleagues also reported that porous structures enhance cell attachment [26]. Lamellipodia and filopodia are two important cytoplasmic protrusions that are closely related to cell migration [27,28]. Migrating cells move using their lamellipodia [29]. Cells on micron- and submicron-scale structures have been observed to enter pores and attach to the substrate via their filopodia [26]. Lee et al. reported that filopodia contribute to cell motility by functioning as antennae for detecting the surroundings of the cell [30]. Consistent with the results of previous studies, our results showed that cells on the surface of the DMF group possessed more prominent lamellipodia and filopodia.

Shear strength also increases, with greater integration between implants and bone, with increased surface porosity $[31,32]$. Our study indicates that the bonding strength was 2.5 times higher in the highly porous SUS-DMF group than in the SUS-machined group, which was probably related to the higher degree of bone-to-implant contact in the SUS-DMF group. Svehla et al. reported that porous Ti implants possessed greater shear strength than Ti grit-blasted implants or hydroxyapatite-coated Ti grit-blasted implants [32]. Surfaces with greater porosity and roughness enhance the biomechanical characteristics at the interface in bone-anchored implants by providing mechanical interlocking [33]. In our previous study, the DMF group possessed a tensile strength $17.5 \%$ greater and a shear strength $10.2 \%$ greater than when coatings were applied using Ti plasma spray [20].

There are several limitations to this study. First, we did not compare the DMF method with other 3D printing methods (such as SLM and EBM), and only performed a comparison with machined SUS, so it is uncertain on the basis of the results of this study whether the favorable result of SUS-DMF is because the SUS is coated with a non-SUS material, or is due to the Ti coating. Further studies are required to determine whether this method shows better osseointegration and mechanical strength than other 3D methods. Second, a DNA study was not carried out in this study. Further DNA studies could reinforce these findings by performing an evaluation of the levels of type I collagen and osteocalcin.

\section{Conclusions}

We found that the Ti coating on SUS316L stainless steel manufactured by DMF using the metal 3D printing technique was superior to machined SUS316L with respect to biological responses. The DMF specimens showed better surface characteristics and biomechanical properties than the machined SUS316L, both in vitro and in vivo. In addition, this method is cost-effective and uses an automated manufacturing process. Thus, DMF with metal 3D printing can be applied for many metals for the production and processing of prostheses.

Author Contributions: T.-I.K., S.-W.L., W.-L.J., Y.-S.K. and Y.-W.L. designed the study; T.-I.K., S.-W.L., Y.-S.K. and S.-C.K. performed the experiments; W.-L.J., S.-Y.K. and Y.-W.L. contributed analysis tools; T.-I.K., S.-W.L., Y.-W.L. and S.-Y.K. analyzed the data; Y.-W.L. and S.-W.L. wrote the majority of the article. All authors have read and agreed to the submitted version of the manuscript.

Funding: This research was supported by the Advanced Technology Center Project (10048394) of the Korea Evaluation Institute of Industrial Technology (KR).

Institutional Review Board Statement: Not applicable.

Informed Consent Statement: Not applicable.

Data Availability Statement: The datasets generated during and/or analysed during the current study are available from the corresponding author on reasonable request. 
Acknowledgments: The Catholic MASTER Cells supplied by the Catholic Institute of Cell Therapy (Seoul, Korea) were derived from human bone marrow donated by healthy donors after providing informed consent.

Conflicts of Interest: The authors declare no conflict of interest.

\section{References}

1. Asri, R.I.M.; Harun, W.; Samykano, M.; Lah, N.A.C.; Ghani, S.A.C.; Tarlochan, F.; Raza, M. Corrosion and surface modification on biocompatible metals: A review. Mater. Sci. Eng. C 2017, 77, 1261-1274. [CrossRef] [PubMed]

2. Lim, Y.W.; Kwon, S.Y.; Sun, D.H.; Kim, Y.S. The Otto Aufranc Award: Enhanced Biocompatibility of Stainless Steel Implants by Titanium Coating and Microarc Oxidation. Clin. Orthop. Relat. Res. 2011, 469, 330-338. [CrossRef] [PubMed]

3. Bollero, P.; Di Fazio, V.; Pavoni, C.; Cordaro, M.; Cozza, P.; Lione, R. Titanium alloy vs. stainless steel miniscrews: An in vivo split-mouth study. Eur. Rev. Med. Pharmacol. Sci. 2018, 22, 2191-2198. [PubMed]

4. Brown, R.N.; Sexton, B.E.; Chu, T.M.G.; Katona, T.R.; Stewart, K.T.; Kyung, H.M.; Liu, S.S.Y. Comparison of stainless steel and titanium alloy orthodontic miniscrew implants: A mechanical and his-tologic analysis. Am. J. Orthod. Dentofac. Orthop. 2014, 145, 496-504. [CrossRef]

5. Head, W.C.; Bauk, D.J.; Emerson, R.H. Titanium as the material of choice for cementless femoral components in total hip arthroplasty. Clin. Orthop. Relat. Res. 1995, 1995, 85-90.

6. Mohamed, A.; Rajeev, A.S. Clinical outcomes and complications of titanium versus stainless steel elastic nail in man-agement of paediatric femoral fractures-A systematic review. Eur. J. Orthop. Surg. Traumatol. 2017, 27, 157-167. [CrossRef]

7. Unnanuntana, A.; Dimitroulias, A.; Bolognesi, M.P.; Hwang, K.L.; Goodman, S.B.; Marcus, R.E. Cementless Femoral Prostheses Cost More to Implant than Cemented Femoral Prostheses. Clin. Orthop. Relat. Res. 2008, 467, 1546-1551. [CrossRef]

8. Qiu, Z.-Y.; Chen, C.; Wang, X.-M.; Lee, I.-S. Advances in the surface modification techniques of bone-related implants for last 10 years. Regen. Biomater. 2014, 1, 67-79. [CrossRef]

9. Farias, M.C.M.; Souza, R.M. The influence of applied load, sliding velocity and martensitic transformation on the unlu-bricated sliding wear of austenitic stainless steels. Wear 2007, 263, 773-781. [CrossRef]

10. Disegi, J.; Eschbach, L. Stainless steel in bone surgery. Injury 2000, 31 (Suppl. S4), 2-6. [CrossRef]

11. Huang, S.; Ng, M.; Samandi, M.; Brandt, M. Tribological behaviour and microstructure of TiCxN $(1-x)$ coatings deposited by filtered arc. Wear 2002, 252, 566-579. [CrossRef]

12. Vasconcelos, D.C.L.; Nunes, E.H.M.; Sabioni, A.C.S.; Vasconcelos, P.M.P.; Vasconcelos, W.L. Optical characterization of 316L stainless steel coated with sol-gel titania. J. Non. Cryst. Solids 2012, 358, 3042-3047. [CrossRef]

13. Aksakal, B.; Gavgali, M.; Dikici, B. The Effect of Coating Thickness on Corrosion Resistance of Hydroxyapatite Coated Ti6Al4V and 316L SS Implants. JMEPEG 2010, 19, 894-899. [CrossRef]

14. Shaigan, N.; Qu, W.; Ivey, D.G.; Chen, W. A review of recent progress in coatings, surface modifications and alloy developments for solid oxide fuel cell ferritic stainless steel interconnects. J. Power Sources 2010, 195, 1529-1542. [CrossRef]

15. Chicot, D.; Puchi-Cabrera, E.S.; Decoopman, X.; Roudet, F.; Lesage, J.; Staia, M.H. Diamond like carbon coatings deposited on nitrided 316L stainless steel substrate: A hard-ness depthhardening profile modeling. Diam. Relat. Mater. 2011, 20, 1344-1352. [CrossRef]

16. Purushotham, K.; Ward, L.P.; Brack, N.; Pigram, P.; Evans, P.; Noorman, H.; Manory, R.R. Tribological studies of Zr-implanted PVD TiN coatings deposited on stainless steel substrates. Wear 2003, 254, 589-596. [CrossRef]

17. Vite, M.; Moreno-Rios, M.; Hernández, E.G.; Laguna-Camacho, J. A study of the abrasive resistance of sputtered CrN coatings deposited on AISI 316 and AISI H13 steel substrates using steel particles. Wear 2011, 271, 1273-1279. [CrossRef]

18. Saravanan, I.; Perumal, A.E.; Issac, F.; Vettivel, S.; Devaraju, A. Optimization of wear parameters and their relative effects on TiN coated surface against Ti6Al4V alloy. Mater. Des. 2016, 92, 23-35. [CrossRef]

19. Devaraju, A.; Elayaperumal, A.; Alphonsa, J.; Kailas, S.V.; Venugopal, S. Microstructure and Dry Sliding Wear Resistance Evaluation of Plasma Nitride Treated Austenitic Stainless Steel Type AISI 316LN against Different Sliders. Surf. Coat. Technol. 2012, 207, 406-412. [CrossRef]

20. Shin, T.; Park, S.J.; Kang, K.S.; Kim, J.S.; Kim, Y.; Lim, Y.; Lim, D. A laser-aided direct metal tooling technology for artificial joint surface coating. Int. J. Precis. Eng. Manuf. 2017, 18, 233-238. [CrossRef]

21. Kim, S.C.; Jo, W.L.; Kim, Y.S.; Kwon, S.Y.; Cho, Y.S.; Lim, Y.W. Titanium Powder Coating Using Metal 3D Printing: A Novel Coating Technology for Cobalt-Chromium Alloy Implants. Tissue Eng. Regen. Med. 2019, 16, 11-18. [CrossRef]

22. Sing, S.L.; An, J.; Yeong, W.Y.; Wiria, F.E. Laser and electron-beam powder-bed additive manufacturing of metallic implants: A review on processes, materials and designs. J. Orthop. Res. 2016, 34, 369-385. [CrossRef]

23. Balla, V.K.; Banerjee, S.; Bose, S.; Bandyopadhyay, A. Direct laser processing of a tantalum coating on titanium for bone replacement structures. Acta Biomater. 2010, 6, 2329-2334. [CrossRef] [PubMed]

24. Schuler, M.; Trentin, D.; Textor, M.; Tosatti, S.G.P. Biomedical interfaces: Titanium surface technology for implants and cell carriers. Nanomedicine 2006, 1, 449-463. [CrossRef] [PubMed]

25. Keller, J.C.; Stanford, C.M.; Wightman, J.P.; Draughn, R.A.; Zaharias, R. Characterizations of titanium implant surfaces. III. J. Biomed. Mater. Res. 1994, 28, 939-946. [CrossRef] 
26. Zhu, X.; Chen, J.; Scheideler, L.; Altebaeumer, T.; Geis-Gerstorfer, J.; Kern, D. Cellular Reactions of Osteoblasts to Micron- and Submicron-Scale Porous Structures of Titanium Surfaces. Cells Tissues Organs 2004, 178, 13-22. [CrossRef] [PubMed]

27. Mattila, P.; Lappalainen, P. Filopodia: Molecular architecture and cellular functions. Nat. Rev. Mol. Cell Biol. 2008, 9, 446-454. [CrossRef] [PubMed]

28. Small, J.; Stradal, T.; Vignal, E.; Rottner, K. The lamellipodium: Where motility begins. Trends Cell Biol. 2002, 12, 112-120. [CrossRef]

29. Raucher, D.; Sheetz, M.P. Cell spreading and lamellipodial extension rate is regulated by membrane tension. J. Cell Biol. 2000, 148, 127-136. [CrossRef]

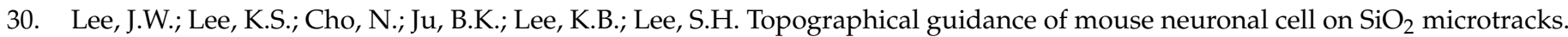
Sens. Actuators B Chem. 2007, 128, 252-257. [CrossRef]

31. Bertollo, N.; Matsubara, M.; Shinoda, T.; Chen, D.; Kumar, M.; Walsh, W.R. Effect of surgical fit on integration of cancellous bone and implant cortical bone shear strength for a porous titanium. J. Arthroplast. 2011, 26, 1000-1007. [CrossRef] [PubMed]

32. Svehla, M.; Morberg, P.; Zicat, B.; Bruce, W.; Sonnabend, D.; Walsh, W. Morphometric and mechanical evaluation of titanium implant integration: Comparison of five surface structures. J. Biomed. Mater. Res. 2000, 51, 15-22. [CrossRef]

33. Durual, S.; Rieder, P.; Garavaglia, G.; Filieri, A.-R.M.; Cattani-Lorente, M.A.; Scherrer, S.S.; Wiskott, H.A. TiNOx coatings on roughened titanium and $\mathrm{CoCr}$ alloy accelerate early osseointegration of dental implants in minipigs. Bone 2013, 52, $230-237$. [CrossRef] [PubMed] 